\title{
High-risk Stage II Colorectal Cancers Carry an Equivalent Risk of Peritoneal Recurrence to Stage III
}

\author{
HIROAKI NOZAWA, KAZUSHIGE KAWAI, KEISUKE HATA, TOSHIAKI TANAKA, TAKESHI NISHIKAWA, \\ KENSUKE OTANI, KAZUHITO SASAKI, MANABU KANEKO, SHIGENOBU EMOTO and KOJI MURONO
}

Department of Surgical Oncology, The University of Tokyo, Tokyo, Japan

\begin{abstract}
Background/Aim: Several risk factors for recurrence have been identified in stage II colorectal cancer. However, in contrast to stage III, the benefits of adjuvant chemotherapy for these patients remain controversial. We hypothesized that the different impacts of chemotherapy may be due to different patterns of recurrence between these stages. The aim of this study was to characterize recurrence in high-risk stage II colorectal cancer $(C R C)$ in comparison with stage III. Patients and Methods: A total of 442 patients with curatively resected stage III and high-risk stage II CRCs were evaluated. The recurrence site and frequency were compared between these stages. The risk factors of recurrence by site were identified using multivariate analyses. Results: During the follow-up (median: 6.4 years), $31 \%$ of stage III and 13\% of high-risk stage II patients manifested recurrence. Recurrence in the liver, lung, and distant lymph nodes was significantly more frequent in stage III $(18 \%, 12 \%, 11 \%)$ than in high-risk stage II $(7 \%, 6 \%, 3 \%)$. Stage III was independently associated with recurrence in these organs. In contrast, the rate of peritoneal recurrence was $5 \%$ in both stages. Conclusion: Clinicians should be aware that high-risk stage II CRC has a similar risk of postoperative recurrence in the peritoneum to Stage III CRC.
\end{abstract}

Colorectal cancer (CRC) is the third most common cancer in the world with approximately 1.4 million new patients being diagnosed annually $(1,2)$. Stage III CRC needs to be treated surgically and then with adjuvant chemotherapy, as indicated

This article is freely accessible online.

Correspondence to: Hiroaki Nozawa, MD, PhD, Department of Surgical Oncology, The University of Tokyo, 7-3-1 Hongo, Bunkyo-ku, Tokyo 113-8655, Japan. Tel: +81 358008653, Fax: +81 338116822, e-mail: hiroanozawa-gi@umin.ac.jp

Key Words: Colorectal cancer, high-risk stage II, stage III, peritoneal metastasis. by the guidelines (3-6). On the other hand, surgical resection is the mainstay of treatments for stage II CRCs that less frequently manifest recurrent disease. The American Society of Clinical Oncology (ASCO), the National Comprehensive Cancer Network (NCCN), and the European Society for Medical Oncology (ESMO) previously proposed many risk factors for postoperative recurrence in stage II CRC such as pathological T4, poorly differentiated histology, suboptimal lymph node retrieval, bowel perforation, bowel obstruction, lymphatic and venous invasion, perineural invasion, and positive resection margins $(3,4,7,8)$. After the concept of high-risk stage II CRC emerged, extensive information was obtained on overall recurrence rates; however, recurrence sites have not yet been investigated in detail.

CRC may disseminate via lymphatic and hematogenous routes or spread intraperitoneally. In combination with systemic chemotherapy, metastasized site-oriented locoregional therapies, e.g. intraportal chemotherapy for liver recurrence and intraperitoneal chemotherapy for peritoneal recurrence, are considered to be reasonable (9). Previous randomized trials using these combinational therapies reported increased survival rates in CRC patients with high-risk for recurrence in specific organs, even in the adjuvant setting (9), underscoring the importance of comprehending recurrence patterns in more detail in curatively resected CRC.

The aim of the present study, was to characterize recurrence in high-risk stage II CRC in comparison with stage III.

\section{Patients and Methods}

Patients. Patients with primary CRC resected curatively (R0 resection) at the Department of Surgical Oncology, the University of Tokyo between January 2005 and 2012 were retrospectively searched. Among these patients, those who were finally diagnosed with stage III or high-risk stage II CRC and were followed-up for at least five years were reviewed. As high-risk stage II, cases of pathological T4, a poorly differentiated histology, less than 12 harvested lymph nodes, bowel obstruction, bowel perforation, or lymphatic/venous invasion were selected according to the major guidelines $(3,4,7,8)$. Perineural invasion was not analyzed because 
Table I. Clinicopathological factors in stage III and high-risk stage II CRC.

\begin{tabular}{|c|c|c|c|}
\hline Parameter & $\begin{array}{l}\text { Stage III } \\
(\mathrm{n}=234)\end{array}$ & $\begin{array}{l}\text { High-risk stage II } \\
\qquad(\mathrm{n}=208)\end{array}$ & $p$-Value \\
\hline \multicolumn{4}{|l|}{ Age (years) } \\
\hline Mean \pm SD & $66.2 \pm 11.6$ & $68.3 \pm 11.0$ & 0.053 \\
\hline \multicolumn{4}{|l|}{ Gender } \\
\hline Male & $139(59 \%)$ & $123(59 \%)$ & 0.95 \\
\hline \multicolumn{4}{|l|}{$\operatorname{BMI}\left(\mathrm{kg} / \mathrm{m}^{2}\right)$} \\
\hline Mean \pm SD & $22.8 \pm 3.4$ & $22.9 \pm 3.6$ & 0.79 \\
\hline \multicolumn{4}{|l|}{ Serum CEA } \\
\hline Elevated & $98(42 \%)$ & $97(47 \%)$ & 0.34 \\
\hline \multicolumn{4}{|l|}{ Serum CA 19-9 } \\
\hline Elevated & $39(17 \%)$ & $25(12 \%)$ & 0.18 \\
\hline \multicolumn{4}{|l|}{ Location } \\
\hline Right-sided colon & $83(35 \%)$ & $81(39 \%)$ & 0.66 \\
\hline Left-sided colon & $110(47 \%)$ & $96(46 \%)$ & \\
\hline Rectum & $41(18 \%)$ & $31(15 \%)$ & \\
\hline \multicolumn{4}{|l|}{ Size $(\mathrm{mm})$} \\
\hline Mean \pm SD & $42.4 \pm 1.4$ & $50.6 \pm 1.4$ & $<0.0001$ \\
\hline \multicolumn{4}{|c|}{ Obstruction/Perforation } \\
\hline Present & $72(31 \%)$ & $83(40 \%)$ & 0.045 \\
\hline \multicolumn{4}{|l|}{ Histology } \\
\hline Differentiated & $219(94 \%)$ & $195(94 \%)$ & 0.95 \\
\hline Undifferentiated & $15(6 \%)$ & $13(6 \%)$ & \\
\hline \multicolumn{4}{|l|}{ Lymphatic invasion } \\
\hline Present & $119(51 \%)$ & $35(17 \%)$ & $<0.0001$ \\
\hline \multicolumn{4}{|l|}{ Venous invasion } \\
\hline Present & $187(80 \%)$ & $159(76 \%)$ & 0.43 \\
\hline \multicolumn{4}{|c|}{ Harvested lymph nodes } \\
\hline$<12$ & $41(18 \%)$ & $41(20 \%)$ & 0.55 \\
\hline \multicolumn{4}{|l|}{ Depth } \\
\hline $\mathrm{pT} 1 / \mathrm{pT} 2$ & $47(20 \%)$ & 0 & $<0.0001$ \\
\hline pT3 & $121(52 \%)$ & $155(75 \%)$ & \\
\hline pT4 & $66(28 \%)$ & $53(25 \%)$ & \\
\hline
\end{tabular}

CRC: Colorectal cancer; SD: standard deviation; BMI: body mass index; CEA: carcinoembryonic antigen; CA 19-9: carbohydrate antigen 19-9.

this parameter was not systematically evaluated during the aforementioned study period. Patients with multiple primary CRCs and inflammatory bowel disease-associated cancer as well as those who received preoperative chemotherapy and/or radiation therapy were excluded. Patients who had simultaneously other malignancies or were lost to the follow-up before five years were also excluded.

All patient data regarding gender, age, serum tumor markers such as carcinoembryonic antigen (CEA) and carbohydrate antigen (CA) 19-9 just before surgery, and the pathological parameters of the primary tumor, namely, location, size, and stage in addition to the risk factors described above were retrieved.

The normal upper limits of serum CEA and CA $19-9$ are $5 \mathrm{ng} / \mathrm{ml}$ and $37 \mathrm{U} / \mathrm{ml}$, respectively. The histopathological description of primary CRC was based on the eighth edition of the American Joint Committee on Cancer and the International Union Against Cancer Tumor-Node Metastasis (AJCC/UICC TNM) grading system (10).

Follow-up. Computed tomography (CT) scans were performed six months after surgery or at the end of adjuvant chemotherapy, and
Table II. Adjuvant chemotherapy and recurrence in stage III and highrisk stage II CRC.

\begin{tabular}{lccc}
\hline Parameter & $\begin{array}{c}\text { Stage III } \\
(\mathrm{n}=234)\end{array}$ & $\begin{array}{c}\text { High-risk stage II } \\
(\mathrm{n}=208)\end{array}$ & $p$-Value \\
& & & \\
\hline Adjuvant CTX & & & \\
$\quad$ Any & $157(67 \%)$ & $14(7 \%)$ & $<0.0001$ \\
5-FU (+ LV) & $138(88 \%)^{\mathrm{a}}$ & $14(100 \%)^{\mathrm{a}}$ & 0.37 \\
5-FU + oxaliplatin & $19(12 \%)^{\mathrm{a}}$ & 0 & \\
Recurrence & & & \\
Overall & $73(31 \%)$ & $28(13 \%)$ & $<0.0001$ \\
Liver & $41(18 \%)$ & $15(7 \%)$ & 0.0015 \\
Lung & $29(12 \%)$ & $13(6 \%)$ & 0.028 \\
Lymph nodes & $26(11 \%)$ & $6(3 \%)$ & 0.0008 \\
Peritoneum & $11(5 \%)$ & $10(5 \%)$ & 1.00 \\
Local & $8(4 \%)$ & $2(1 \%)$ & 0.12 \\
Bone & $2(1 \%)$ & $1(0 \%)$ & 1.00 \\
Brain & $4(2 \%)$ & 0 & 0.13 \\
Others & $9(4 \%)$ & $2(1 \%)$ & 0.067 \\
\hline
\end{tabular}

CRC: Colorectal cancer; CTX: chemotherapy; 5-FU: 5-fluorouracil; LV: levofolinate. apercentage in patients who received chemotherapy as the denominator.

every six to twelve months thereafter. When serum tumor marker levels increased in a rapid manner or a new manifestation of symptoms occurred suggesting recurrent disease, CT scans and other imaging modalities such as magnetic resonance imaging and positron emission tomography were additionally performed. Recurrence-free survival (RFS) was defined as the period between the date of surgery and diagnosis of any recurrence. The indication for adjuvant chemotherapy depended on doctors' discretion and patients' conditions and preferences. Dose reductions and the cessation of chemotherapy were considered based on the patient's condition and preference. Basically, adjuvant chemotherapy regimens included oral or infusional 5-FU plus levofolinate (LV), or a 5-FU and oxaliplatinbased regimen such as FOLFOX for six months $(3,4,11,12)$.

Ethical approval. The study protocol was approved by the local ethics committees in the University of Tokyo [reference number: 3252-(5)], and thus meets the standards of the Declaration of Helsinki in its revised version of 1975 and its later amendments.

Statistical analysis. The Student's $t$-test or Mann-Whitney test was used to compare continuous variables, and the Chi-squared test or Fisher's exact test was employed to compare categorical data. Serum CEA and CA 19-9 were dichotomized by preset cut-off levels as described above. Site-specific recurrence rates were estimated by the Kaplan-Meier method and were compared using the Log-rank test. Cox's proportional-hazard model was performed to evaluate the relationship between perioperative clinicopathological factors and recurrence, in which continuous variables other than tumor markers were dichotomized by their mean values (age, BMI, and tumor size). If factors showed a $p$-value of less than 0.1 in the univariate analysis, these parameters were included in the multivariate analysis as explanatory variables. All statistical analyses of data were performed using JMP Version 13.0.0 (SAS Institute Inc., Cary, NC, USA), with $p$-values less than 0.05 being considered significant. 


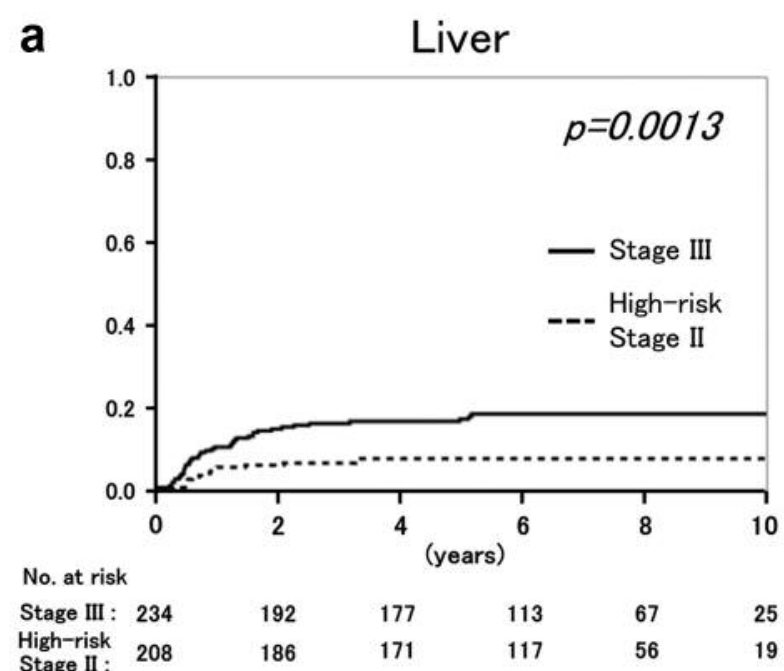

C

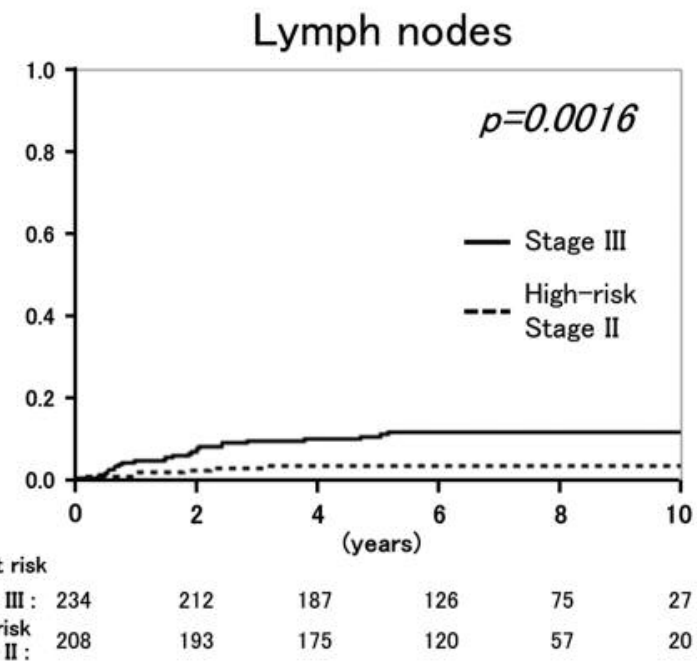

b

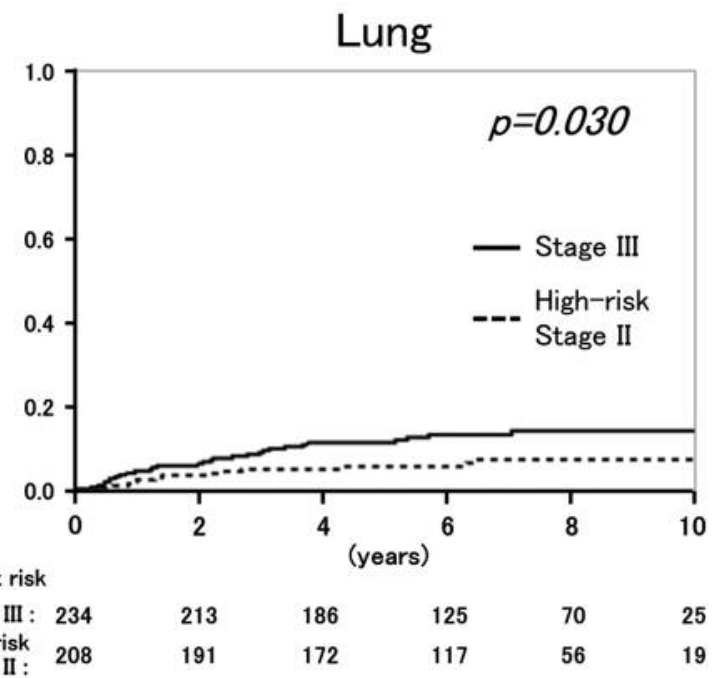

d

Peritoneum

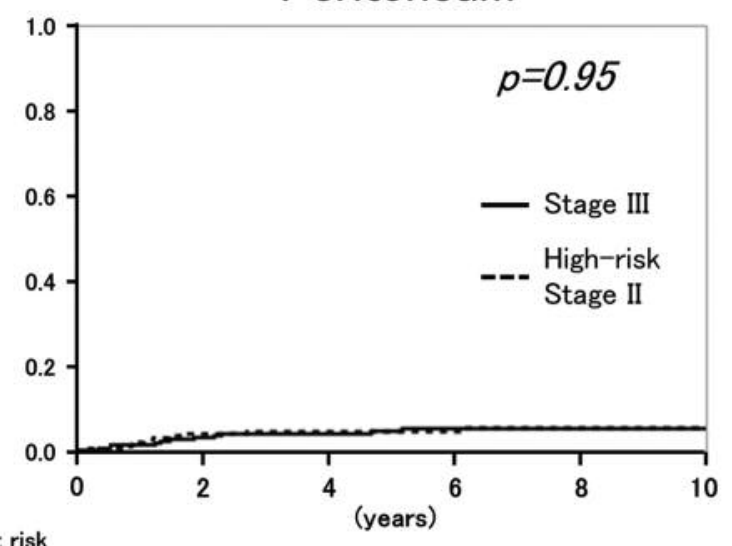

No. at risk

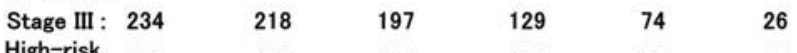

$\begin{array}{lllllll}\text { High-risk } & 208 & 189 & 175 & 121 & 58 & 20\end{array}$

Figure 1. Organ-specific recurrence rate $(A)$ recurrence in the liver, $(B)$ recurrence in the lung, $(C)$ recurrence in distant lymph nodes, and $(D)$ recurrence in the peritoneum.

\section{Results}

Patient overview. A total of 442 patients were identified to have stage III or high-risk stage II CRC. In 208 stage II CRCs, obstruction was the leading "high risk" factor (81 patients, 39\%), followed by pathological T4 (53 patients, $25 \%)$. Table I summarizes the profile of patients examined in the present study. High-risk stage II CRCs were larger than stage III CRCs by $8 \mathrm{~mm}$. Obstructive cancer was also more frequent in high-risk stage II $(40 \%)$ than in stage III $(31 \%)$. On the other hand, lymphatic invasion was more frequently observed in stage III $(51 \%)$ than in high-risk stage II $(17 \%)$. No significant differences were observed in other background parameters between the stages.
One hundred seventy-one patients (39\%) underwent adjuvant chemotherapy after surgery. Most of these patients received 5-FU with or without $\mathrm{LV}$; oxaliplatin was additionally administered to 19 stage III CRC patients (data not shown).

Comparison of recurrence rates between stage III and highrisk stage II. During the median follow-up of 6.4 years, recurrence was observed in $31 \%$ of stage III CRC and $13 \%$ of high-risk stage II $(p<0.0001)$. As shown in Table II, the liver, lung, and distant lymph nodes were metastasized more frequently in stage III $(18 \%, 12 \%$, and $11 \%)$ than in high-risk stage II $(7 \%, p=0.0015,6 \%, p=0.028$, and $3 \%, p=0.0008$, respectively). In contrast, metachronous peritoneal dissemination occurred in stage III and high-risk stage II with 
Table III. Univariate and multivariate analyses of predictive factors for each organ recurrence.

\begin{tabular}{|c|c|c|c|c|}
\hline \multirow[b]{2}{*}{ Organ } & \multirow[b]{2}{*}{ Parameter } & \multirow{2}{*}{$\begin{array}{l}\text { Univariate } \\
p \text {-Value }\end{array}$} & \multicolumn{2}{|c|}{ Multivariate } \\
\hline & & & HR $(95 \% \mathrm{CI})$ & $p$-Value \\
\hline \multirow[t]{3}{*}{ Liver } & Lymphatic invasion ( $v s$. no) & 0.085 & & \\
\hline & Venous invasion (vs. no) & 0.035 & $2.37(1.09-6.21)$ & 0.028 \\
\hline & Stage III ( $v s$. high-risk stage II) & 0.0019 & $2.44(1.33-4.69)$ & 0.0035 \\
\hline \multirow[t]{4}{*}{ Lung } & Elevated CEA ( $v s$. normal) & 0.064 & & \\
\hline & Elevated CA 19-9 (vs. normal) & 0.0004 & $2.60(1.27-5.09)$ & 0.010 \\
\hline & Venous invasion (vs. no) & 0.023 & $3.35(1.21-13.93)$ & 0.017 \\
\hline & Stage III (vs. high-risk stage II) & 0.028 & $1.91(1.01-3.82)$ & 0.046 \\
\hline \multirow[t]{7}{*}{ Lymph nodes } & Male (vs. female) & 0.041 & & \\
\hline & Elevated CA 19-9 (vs. normal) & $<0.0001$ & $4.70(2.26-9.65)$ & $<0.0001$ \\
\hline & Undifferentiated histology ( $v s$. differentiated) & 0.035 & & \\
\hline & pT4 (vs. pT1-3) & 0.067 & & \\
\hline & Lymphatic invasion ( $v s$. no) & 0.016 & & \\
\hline & Venous invasion (vs. no) & 0.059 & & \\
\hline & Stage III ( $v s$. high-risk stage II) & 0.0010 & $3.23(1.32-9.10)$ & 0.0089 \\
\hline \multirow[t]{4}{*}{ Peritoneum } & Elevated CA 19-9 (vs. normal) & 0.0059 & & \\
\hline & Undifferentiated histology ( $v s$. differentiated) & 0.038 & $3.96(1.10-11.33)$ & 0.037 \\
\hline & pT4 (vs. pT1-3) & 0.0025 & $3.42(1.41-8.59)$ & 0.0068 \\
\hline & Obstruction/Perforation (vs. no) & 0.015 & & \\
\hline
\end{tabular}

HR: Hazard ratio; CI: confidence interval; CEA: carcinoembryonic antigen; CA 19-9: carbohydrate antigen 19-9.

the same frequencies (5\% and 5\%,p=1.00). Figure 1 shows site-specific recurrence rates over time according to stage. Stage III CRC showed a markedly higher rate of recurrence in the liver, lung, and distant lymph nodes than high-risk stage II. However, the recurrence rate curves of the peritoneum were superimposed for both stages.

Predictive factors of recurrence in each organ. A univariate analysis was performed using Cox's proportional hazards model in order to identify clinicopathological predictors of recurrence in each organ. As shown in Table III, stage III correlated with recurrence in the liver (hazard ratio $(\mathrm{HR})=2.44, p=0.0035)$, lung $(\mathrm{HR}=1.91, p=0.0046)$, and lymph nodes $(\mathrm{HR}=3.33, p=0.0089)$. In contrast, peritoneal recurrence correlated with an undifferentiated histology $(\mathrm{HR}=3.96, p=0.037)$ and pT4 $(\mathrm{HR}=3.42, p=0.0068)$, whereas stage III was not an independent predictor for peritoneal recurrence. Adjuvant chemotherapy was not associated with recurrence at any site.

\section{Discussion}

Previous studies reported the overall frequency of postoperative recurrence and predictive factors in stage II and III CRCs (13-19). However, limited information is currently available on recurrence rates in terms of metastasized organs. Russell et al. analyzed the pattern of recurrence of colon cancer according to the lymph node status; no significant differences were observed in local, peritoneal, or distant metastases between node-negative and -positive cases (20). Sadahiro et al. reported the number of stage II and III CRC patients who relapsed in a follow-up period of more than 10 years according to the recurrent site. Based on their data, we calculated the rates of metastases in the liver and lung in stage II as $6 \%$ and $3 \%$, respectively, which were significantly lower than those in stage III $(14 \%$ and $11 \%$, respectively). Peritoneal and local recurrence rates were slightly lower in stage II than in stage III patients $(1 \%$ vs. $2 \%$, and $4 \%$ vs. $8 \%$ ) (21). However, these studies were published more than a decade ago when the concept of highrisk stage II was not established. The present study is the first to analyze the site distribution of recurrence after surgery using the largest number of patients with stage III and high-risk stage II CRCs.

The liver, lung, lymph nodes, and peritoneum were identified as the most common organs of recurrence in stage III and high-risk stage II CRCs. Recurrence rates in the liver, lung, and lymph nodes were significantly higher in stage III. In contrast, peritoneal recurrence rates were similar in stage III and high-risk stage II CRCs (Table II and Figure 1). The stage III and high-risk stage II cohorts comprised almost the same percentages of T4 cancers (Table I), which are known risk factors for peritoneal dissemination $(22,23)$. Although the absence of a significant difference may be due to the lack of power, we need to be aware of the similar risk of peritoneal recurrence between high-risk stage II and stage III. 
Adjuvant chemotherapy was not associated with recurrence in the common sites. This is partly due to the potential bias of the indication for chemotherapy and/or insufficient statistical power due to the small number of patients. Although clinicians currently consider adjuvant chemotherapy for patients with any high-risk factor, recent studies reported that survival outcomes were influenced by features not suggested in the guidelines $(13,14)$. On the other hand, Kumar et al. demonstrated that T4 may be the only risk factor for which stage II CRC may obtain survival benefits from adjuvant chemotherapy (24). In this regard, adjuvant chemotherapy oriented towards peritoneal targets such as intraperitoneal chemotherapy in combination with intravenous chemotherapy or hyperthermia might be promising in pT4 CRC $(25,26)$.

Our study had several limitations due to its retrospective nature and single institute experience. As mentioned above, the application and regimen of adjuvant chemotherapy was not based on pre-determined criteria. In addition, a relatively small number of stage III and highrisk stage II patients received adjuvant chemotherapy because the study period spanned a long time period, during which guidelines regarding chemotherapy were repeatedly revised.

In conclusion, the potential for recurrence in the peritoneum was similar between high-risk stage II and stage III CRCs. A larger number of patients should be examined to confirm the finding, and further studies are needed in order to clarify how to prevent recurrence in these patients using adjuvant chemotherapy.

\section{Conflicts of Interest}

The Authors report no potential conflicts of interest regarding this study.

\section{Acknowledgements}

The study was supported by Grants-in-Aid for Scientific Research (C: grant number;16K07143, C: grant number;16K07161, C: grant number; 17K10620, C: grant number;17K10621 and C: grant number; 17K10623) from Japan Society for the promotion of Science, and by the Project for Cancer Research and Therapeutic Evolution (P-CREATE, grant number: JP17 cm0106502) from the Japan Agency for Medical Research and Development (AMED).

\section{References}

1 Ferlay J, Soerjomataram I, Ervik M, Dikshit R, Eser S, Mathers C, Rebelo M, Parkin DM, Forman D and Bray F: GLOBOCAN 2012, Colorectal Cancer. Estimated Incidence, Mortality and Prevalence Worldwide in 2012. Available from: http://globocan.iarc.fr.

2 Siegel RL, Miller KD, Fedewa SA, Ahnen DJ, Meester RGS, Barzi A and Jemal A: Colorectal cancer statistics, 2017. CA Cancer J Clin 67: 177-193, 2017.
3 National Comprehensive Cancer Network: Clical Practice Guidelines in Oncology, Colon Cancer, version 1, 2018. https://www.nccn.org/professionals/physician_gls/pdf/colon.pdf.

4 National Comprehensive Cancer Network: Clinical Practice Guidelines in Oncology, Rectal Cancer, version 4, 2017. https://www.nccn.org/professionals/physician_gls/pdf/rectal.pdf.

5 Schmoll HJ, Van Cutsem E, Stein A, Valentini V, Glimelius B, Haustermans K, Nordlinger B, van de Velde CJ, Balmana J, Regula J, Nagtegaal ID, Beets-Tan RG, Arnold D, Ciardiello F, Hoff P, Kerr D, Köhne CH, Labianca R, Price T, Scheithauer W, Sobrero A, Tabernero J, Aderka D, Barroso S, Bodoky G, Douillard JY, El Ghazaly H, Gallardo J, Garin A, Glynne-Jones R, Jordan K, Meshcheryakov A, Papamichail D, Pfeiffer P, Souglakos I, Turhal S and Cervantes A: ESMO Consensus Guidelines for management of patients with colon and rectal cancer. A personalized approach to clinical decision making. Ann Oncol 23: 2479-2516, 2012.

6 Watanabe T, Muro K, Ajioka Y, Hashiguchi Y, Ito Y, Saito Y, Hamaguchi T, Ishida $H$, Ishiguro M, Ishihara S, Kanemitsu $Y$, Kawano H, Kinugasa Y, Kokudo N, Murofushi K, Nakajima T, Oka S, Sakai Y, Tsuji A, Uehara K, Ueno H, Yamazaki K, Yoshida M, Yoshino T, Boku N, Fujimori T, Itabashi M, Koinuma N, Morita T, Nishimura G, Sakata Y, Shimada Y, Takahashi K, Tanaka S, Tsuruta O, Yamaguchi T, Yamaguchi N, Tanaka T, Kotake K and Sugihara K; Japanese Society for Cancer of the Colon and Rectum: Japanese Society for Cancer of the Colon and Rectum (JSCCR) guidelines 2016 for the treatment of colorectal cancer. Int J Clin Oncol 23: 1-34, 2018.

7 Benson AB 3rd, Schrag D, Somerfield MR, Cohen AM, Figueredo AT, Flynn PJ, Krzyzanowska MK, Maroun J, McAllister P, Van Cutsem E, Brouwers M, Charette M and Haller DG: American Society of Clinical Oncology recommendations on adjuvant chemotherapy for stage II colon cancer. J Clin Oncol 22: 3408-3419, 2004.

8 Labianca R, Nordlinger B, Beretta GD, Mosconi S, Mandala M, Cervantes A, Arnold D and Group EGW: Early colon cancer: ESMO clinical practice guidelines for diagnosis, treatment and follow-up. Ann Oncol 24: vi64-vi72, 2013.

9 Rougier P and Nordlinger B: Large scale trial for adjuvant treatment in high risk resected colorectal cancers. Rationale to test the combination of loco-regional and systemic chemotherapy and to compare 1-leucovorin +5 -FU to levamisole +5 -FU. Ann Oncol 4: 21-28, 1993.

10 Brierley JD, Gospodarowicz MK and Wittekind Ch: TNM Classification of Malignant Tumors, ed 8, Oxford, WileyBlackwell, 2016.

11 André T, Boni C, Mounedji-Boudiaf L, Navarro M, Tabernero J, Hickish T, Topham C, Zaninelli M, Clingan P, Bridgewater J, Tabah-Fisch I and de Gramont A: Multicenter international study of oxaliplatin/5-fluorouracil/leucovorin in the adjuvant treatment of colon cancer (mosaic) investigators: Oxaliplatin, fluorouracil, and leucovorin as adjuvant treatment for colon cancer. N Engl J Med 350: 2343-2351, 2004.

12 Twelves C, Wong A, Nowacki MP, Abt M, Burris H 3rd, Carrato A, Cassidy J, Cervantes A, Fagerberg J, Georgoulias V, Husseini F, Jodrell D, Koralewski P, Kröning H, Maroun J, Marschner N, McKendrick J, Pawlicki M, Rosso R, Schüller J, Seitz JF, Stabuc B, Tujakowski J, Van Hazel G, Zaluski J and Scheithauer W: Capecitabine as adjuvant treatment for stage III colon cancer. $\mathrm{N}$ Engl J Med 352: 2696-2704, 2005. 
13 Quah HM, Chou JF, Gonen M, Shia J, Schrag D, Landmann RG, Guillem JG, Paty PB, Temple LK, Wong WD and Weiser MR: Identification of patients with high-risk stage II colon cancer for adjuvant therapy. Dis Colon Rectum 51: 503-507, 2008.

14 Lin CC, Lin JK, Chang SC, Wang HS, Yang SH, Jiang JK, Chen WS and Lin TC: Is adjuvant chemotherapy beneficial to high risk stage II colon cancer? Analysis in a single institute. Int $\mathrm{J}$ Colorectal Dis 24: 665-676, 2009.

15 Sato H, Maeda K, Sugihara K, Mochizuki H, Kotake K, Teramoto T, Kameoka S, Saito Y, Takahashi K, Hirai T, Ohue M, Shirouzu K, Sakai Y, Watanabe T, Hirata K and Hatakeyama $\mathrm{K}$ : High-risk stage II colon cancer after curative resection. J Surg Oncol 104: 45-52, 2011.

16 Lin HH, Chang YY, Lin JK, Jiang JK, Lin CC, Lan YT, Yang SH, Wang HS, Chen WS, Lin TC and Chang SC: The role of adjuvant chemotherapy in stage II colorectal cancer patients. Int J Colorectal Dis 29: 1237-1243, 2014.

17 Nikberg M, Chabok A, Letocha H, Kindler C, Glimelius B and Smedh K: Lymphovascular and perineural invasion in stage II rectal cancer: a report from the Swedish Colorectal Cancer Registry. Acta Oncol 55: 1418-1424, 2016.

18 Hoshino N, Hasegawa S, Hida K, Kawada K, Ganeko R, Sugihara K and Sakai Y: Nomogram for predicting recurrence in stage II colorectal cancer. Acta Oncol 55: 1414-1417, 2016.

19 Nozawa H, Ishihara S, Kawai K, Hata K, Kiyomatsu T, Tanaka T, Nishikawa T, Otani K, Yasuda K, Sasaki K, Murono K and Watanabe T: A high preoperative carbohydrate antigen 19-9 level is a risk factor for recurrence in stage II colorectal cancer. Acta Oncol 56: 634-638, 2017.

20 Russell AH, Tong D, Dawson LE and Wisbeck W: Adenocarcinoma of the proximal colon. Sites of initial dissemination and patterns of recurrence following surgery alone. Cancer 53: 360-367, 1984.

21 Sadahiro S, Suzuki T, Ishikawa K, Nakamura T, Tanaka Y, Masuda T, Mukoyama S, Yasuda S, Tajima T, Makuuchi H and Murayama C: Recurrence patterns after curative resection of colorectal cancer in patients followed for a minimum of ten years. Hepatogastroenterology 50: 1362-1366, 2003.
22 Yang SH, Lin JK, Lai CR, Chen CC, Li AF, Liang WY and Jiang JK: Risk factors for peritoneal dissemination of colorectal cancer. J Surg Oncol 87: 167-173, 2004.

23 Lemmens VE, Klaver YL, Verwaal VJ, Rutten HJ, Coebergh JW and de Hingh $\mathrm{IH}$ : Predictors and survival of synchronous peritoneal carcinomatosis of colorectal origin: a populationbased study. Int J Cancer 128: 2717-2725, 2011.

24 Kumar A, Kennecke HF, Renouf DJ, Lim HJ, Gill S, Woods R, Speers $\mathrm{C}$ and Cheung WY: Adjuvant chemotherapy use and outcomes of patients with high-risk versus low-risk stage II colon cancer. Cancer 12: 527-534, 2015.

25 Scheithauer W, Kornek GV, Marczell A, Karner J, Salem G, Greiner R, Burger D, Stöger F, Ritschel J, Kovats E, Vischer $\mathrm{HM}$, Schneeweiss B and Depisch D: Combined intravenous and intraperitoneal chemotherapy with fluorouracil + leucovorin vs fluorouracil + levamisole for adjuvant therapy of resected colon carcinoma. Br J Cancer 77: 1349-1354, 1998.

26 Klaver CE, Musters GD, Bemelman WA, Punt CJ, Verwaal VJ, Dijkgraaf MG, Aalbers AG, van der Bilt JD, Boerma D, Bremers AJ, Burger JW, Buskens CJ, Evers P, van Ginkel RJ, van Grevenstein WM, Hemmer PH, de Hingh IH, Lammers LA, van Leeuwen BL, Meijerink WJ, Nienhuijs SW, Pon J, Radema SA, van Ramshorst B, Snaebjornsson P, Tuynman JB, Te Velde EA, Wiezer MJ and de Wilt JH: Adjuvant hyperthermic intraperitoneal chemotherapy (HIPEC) in patients with colon cancer at high risk of peritoneal carcinomatosis; the COLOPEC randomized multicentre trial. BMC Cancer 15: 428, 2015.

Received February 25, 2018

Revised May 30, 2018

Accepted June 4, 2018 